\title{
Inhaled Fluorescent Magnetic Nanoparticles Induced Extramedullary Hematopoiesis in the Spleen of Mice
}

\author{
Jung-Taek Kwon ${ }^{1}$, Dae-Seong Kim ${ }^{4}$, , Arash Minai-Tenrani ${ }^{1}$, Soon-Kyung Hwang ${ }^{1}$, \\ Seung-Hee Chang ${ }^{1}$, Eun-Sun LeE ${ }^{1}$, Cheng-Xiong Xu ${ }^{1}$, Hwang Tae Lim ${ }^{1,2}$, Ji-Eun Kim ${ }^{1,2}$, \\ Byung-Il Yoon ${ }^{5}$, Gil-Hwan An ${ }^{6}$, Kee-Ho LeE ${ }^{7}$, Jin-Kyu LeE ${ }^{2,3}$ and Myung-Haing $\mathrm{CHO}^{1,2}$ \\ ${ }^{1}$ Laboratory of Toxicology, College of Veterinary Medicine, ${ }^{2}$ Nano Systems Institute-National Core Research \\ Center, ${ }^{3}$ Materials Chemistry Laboratory, School of Chemistry, Seoul National University, ${ }^{4} \mathrm{HCT}$, ${ }^{5}$ School of \\ Veterinary Medicine, Kangwon National University, ${ }^{6}$ Department of Food Science and Technology, College of \\ Agriculture and Life Sciences, Chungnam National University and ${ }^{7}$ Laboratory of Molecular Oncology, Division \\ of Radiation Cancer Research, Korea Institute of Radiological and Medical Sciences, Korea \\ "Present address: Environmental Science and Engineering, Gwangju Institute of Science and Technology, Korea
}

\begin{abstract}
Inhaled Fluorescent Magnetic Nanoparticles Induced Extramedullary Hematopoiesis in the Spleen of Mice: Jung-Taek Kwon, et al. Laboratory of Toxicology, College of Veterinary Medicine, Seoul National University, Korea-Objectives: Nanomaterials are used in a wide variety of industrial materials such as semiconductors, magnetic resonance imaging, gene delivery carriers for gene therapy and many others; thus, human seems to be frequently exposed to them. Such diverse applications of nanoparticles elicit the need to identify the positive aspects of nanomaterials while avoiding the potential toxic effects. In this study, inhalation toxicity of manufactured nanomaterials using fluorescent magnetic nanoparticles (FMNPs) was assessed to address the issue of potential nanoparticle toxicity. Methods: Biological samples from a previous mouse FMNP exposure experiment were analyzed for potential FMNP toxicity. Mice inhaled FMNPs for 4 wk through a nose-only exposure chamber developed by our group for 4 wk and the potential toxicity of FMNPs was analyzed. Results: The nanoparticle distribution by scanning mobility particle sizer (SMPS) analysis showed that the mean values of number concentration (mass concentrations) in the nose-only exposure chamber were maintained at $4.89 \times 10^{5} / \mathrm{cm}^{3}$ (approximately $159.4 \mu \mathrm{g} / \mathrm{m}^{3}$ ) for the low concentration and $9.34 \times 10^{5} / \mathrm{cm}^{3}$ (approximately $319.5 \mu \mathrm{g} / \mathrm{m}^{3}$ ) for the high concentration, respectively. Inhalation of FMNPs
\end{abstract}

Received Nov 15, 2008; Accepted Jul 10, 2009

Published online in J-STAGE Aug 25, 2009

Correspondence to: M.-H. Cho, Laboratory of Toxicology, College of Veterinary Medicine, Seoul National University, 599 KwanakRo, Seoul 151-742, Korea (e-mail: mchotox@snu.ac.kr) caused a decrease of body weight and significant changes of white blood cells (WBCs) levels in whole blood. The FMNPs induced extramedullary hematopoiesis in the spleen without having a pulmonary effect. Conclusions: Our results support the proposition that extensive toxicity evaluation is needed for practical applications of anthropogenic nanomaterials and suggest that careful regulation of nanoparticle applications may be necessary to maintain a high quality of life as well as for facilitating the development of nanotechnology.

(J Occup Health 2009; 51: 423-431)

Key words: Extramedullary hematopoiesis, Fluorescent magnetic nanoparticles (FMNPs), Inhalation, Spleen

Nanoparticles are defined as particles with a diameter of less than $100 \mathrm{~nm}$ and they may have toxic effects ${ }^{1)}$. Many studies have demonstrated that various types of nanoparticles can cause lung fibrosis, inflammatory responses, epithelial cell hyperplasia, inhibit phagocytosis, or increase chemokine expression and oxidative stress $^{2-4}$. Recently, magnetic nanoparticles have been introduced as contrast agents for magnetic resonance imaging (MRI), magnetic recording media and gene delivery carriers for gene therapy ${ }^{5-7)}$. Such diverse applications of nanoparticles elicit the need to identify the positive aspects of nanomaterials while avoiding the potential toxic effects. In this study, the inhalation toxicity of manufactured nanomaterials was assessed using fluorescent magnetic nanoparticles (FMNPs) to address the issue of potential nanoparticle toxicity.

In our previous study, we reported the successful 
synthesis of amorphous silica-overcoated magnetic nanoparticles (MNPs) containing fluorescent rhodamineB-isothiocyanate (RITC) within a silica shell of controllable thickness for applications such as bioseparation, high throughput screening, and drug/gene complex delivery ${ }^{8)}$. The advantages of fluorescent magnetic nanoparticles (FMNPs) in toxicity studies are that tissue distribution can be easily performed due to photostable fluorescent RITC dye, and precise quality control of FMNP synthesis precludes confounding factors that may arise from uncontrolled size and surface.

We have already demonstrated the body distribution of FMNPs inhaled by mice ${ }^{9)}$. The FMNPs were distributed in various organs, such as the brain, lung, liver, spleen and kidney. In addition, we showed that these nanoparticles could penetrate the brain by MRI analysis. In this study, we investigated the toxicity of nanoparticles in mice exposed to FMNPs through a nose-only exposure chamber system using the method described in a previous study ${ }^{9)}$.

\section{Materials and Methods}

Fluorescent magnetic nanoparticles (FMNPs) and experiment design

The current study, although it is a stand-alone piece of research, is a continuation of our previous study ${ }^{9}$. For this reason, we used the biological samples of our previous study in order to elucidate detailed information about nanoparticle toxicity in the spleen in terms of extramedullary hematopoiesis. The synthesis of FMNPs and exposure concentrations were described in our previous study ${ }^{8}$ ). Briefly, the total particle number concentration of FMNPs coated with amorphous silica in the nose-only exposure chamber system were maintained at $4.89 \times 10^{5} / \mathrm{cm}^{3}$ for the low concentration and $9.34 \times 105 / \mathrm{cm}^{3}$ for the high concentration. The animals were exposed to FMNPs for 4 wk ( 4 h/day, 5 day/wk) in the nose-only exposure chamber system. The control group was exposed to air filtered by a high efficiency particulate air (HEPA) filter.

\section{Isolation of alveolar macrophages (AMs) and cell} viability assay

Murine alveolar macrophages (AMs) from male C57BL/6 mice (6 wk, SLC Inc, Hamamatsu, Japan) were obtained by repeated whole-lung lavage. The lungs were lavaged five times with $1 \mathrm{~m} l$ of cold PBS (recovery lung lavage fluid, $>85 \%$ ) and then centrifuged at $4^{\circ} \mathrm{C}$ and 600 $\mathrm{g}$ for $10 \mathrm{~min}$ to separate cells. The supernatant was aspirated and discarded, and the cell pellet was resuspended in $1 \mathrm{~m} l$ Dulbecco's Modified Eagle's Medium (DMEM, Biowhittaker, Walkersville, MD, USA) with $10 \%$ heat-inactivated fetal bovine serum and antibiotics (penicillin-streptomycin, Gibco-BRL, Gaithersburg, MD, USA). Cell viability of FMNPs on
AMs was determined by the 3-(4,5-dimethylthiazol-2yl)-2,5-diphenyl-tetrazolium bromide (MTT) assay. AMs were isolated $\left(2 \times 10^{4} /\right.$ well $)$ and placed in 96 -well plate and allowed to adhere to the plate for $4 \mathrm{~h}$ in a humidified incubator $\left(37^{\circ} \mathrm{C}\right.$ in the $\left.5 \% \mathrm{CO}_{2}\right)$. After incubation, the nonadherent cells were then removed by rinsing twice with DMEM, and adherent AMs were incubated in different concentrations $(62.5-1,000 \mu \mathrm{g} / \mathrm{ml})$ of FMNPs for $24 \mathrm{~h}$.

\section{Cellular uptake of FMNPs}

AMs $\left(2.5 \times 10^{4} /\right.$ well $)$ were placed in glass chamber slides (Lab-Tek, Nalge Nunc, Naperville, IL, USA) and cultured for $4 \mathrm{~h}$ in a humidified incubator $\left(37^{\circ} \mathrm{C}\right.$ and $5 \%$ $\mathrm{CO}_{2}$ ). The nonadherent cells were then removed by rinsing twice with DMEM media, and adherent AMs were incubated with $1,000 \mu \mathrm{g} / \mathrm{m} l, 250 \mu \mathrm{g} / \mathrm{m} l$ and $62.5 \mu \mathrm{g} / \mathrm{m} l$ of FMNPs for 12, 24 and $48 \mathrm{~h}$, respectively. After incubation, the medium was aspirated and non-ingested FMNPs were washed off with PBS, fixed in $4 \%$ paraformaldehyde for $10 \mathrm{~min}$. Cells were stained with hematoxylin and eosin (H\&E) or fixed again with methanol:acetone $(1: 1, \mathrm{v} / \mathrm{v})$. Nuclei were stained with 4',6-diamidino-2-phenylindole (DAPI) for $30 \mathrm{~min}$ at dark room. After washing, coverslips were mounted using ultramount media (Dako, Carpinteria, CA, USA), and the slides were observed under a light microscope (Carl Zeiss Inc., Thornwood, New York, USA) and a confocal laser scanning microscope (CLSM, Carl Zeiss, Jena, Germany).

\section{Statistical analysis}

Statistical differences between exposure groups were analyzed by multiple analysis of variance of analysis (ANOVA) and Duncan's multiple range test using SAS statistical software package version 6.12 (SAS Institute, Cary, NC). The level of significance was set at $p<0.05$ and $p<0.01$.

\section{Results}

Analysis of generated FMNPs in nose-only exposure chamber

Detailed information of FMNPs, such as transmission electron microscopy (TEM) and scanning electron microscope (SEM) images, concentrations of FMNPs in the nose-only exposure chamber and body distributions were published in our previous study ${ }^{9}$. Briefly, to measure the concentration of FMNPs in the nose-only exposure chamber system, a SMPS was used. The results of the SMPS analysis showed that the geometric mean diameter (GMD) and geometric standard deviation (GSD) of the FMNPs in the nose-only exposure chamber system were about $49 \mathrm{~nm}$ and 1.8 , respectively, for the low concentration experiment. In the high concentration experiment, the GMD and GSD of the FMNPs were about $51 \mathrm{~nm}$ and 1.7 , respectively. The percentages of the total 
Table 1. Mortality and body weight of mice inhaling FMNPs for $4 \mathrm{wk}$

\begin{tabular}{|c|c|c|c|c|c|c|}
\hline & \multirow[t]{2}{*}{ Group } & \multirow[t]{2}{*}{ Survival } & \multicolumn{3}{|c|}{ Mean body weight (g) } & \multirow{2}{*}{$\begin{array}{l}\text { Final weight } \\
\text { relative to control }(\%)^{\ddagger}\end{array}$} \\
\hline & & & Initial & Final & Change & \\
\hline \multirow[t]{3}{*}{ Male } & Con & $10 / 10$ & $29.55 \pm 0.70$ & $40.25 \pm 1.58^{\mathrm{a}}$ & $10.70 \pm 1.18$ & \\
\hline & Low & $10 / 10$ & $30.36 \pm 1.35$ & $38.49 \pm 1.88^{\mathrm{ab}}$ & $8.13 \pm 2.47$ & 95.42 \\
\hline & High & $9 / 10$ & $30.37 \pm 0.49$ & $37.84 \pm 1.54^{\mathrm{bc}}$ & $7.46 \pm 1.83$ & 94.00 \\
\hline \multirow[t]{3}{*}{ Female } & Con & $10 / 10$ & $26.35 \pm 1.34$ & $32.68 \pm 1.15^{\mathrm{a}}$ & $6.32 \pm 1.95$ & \\
\hline & Low & $10 / 10$ & $26.35 \pm 0.87$ & $30.06 \pm 2.18^{c}$ & $3.71 \pm 2.17$ & 92.00 \\
\hline & High & $10 / 10$ & $25.96 \pm 1.22$ & $30.20 \pm 0.83^{c}$ & $4.24 \pm 1.62$ & 92.43 \\
\hline
\end{tabular}

Mean \pm SD

Mice of each group $(n=10)$ were exposed to FMNPs through nose-only inhalation for 4 wk. The body weight was measured at the start and end of the 28-day exposure period.

particle number concentration were about $34 \%$ (size range: $13-39 \mathrm{~nm}$ ), $55 \%$ (size range: $40-100 \mathrm{~nm}$ ) and $11 \%$ (size range: 101-521 nm) for the high concentration, and for the low concentration, they were about $38 \%$ (size range: $13-39 \mathrm{~nm}$ ), $53 \%$ (size range: $40-100 \mathrm{~nm}$ ) and $9 \%$ (size range: $101-521 \mathrm{~nm}$ ). The mass concentration of FMNPs in the chamber measured by SMPS showed that the mean values of mass concentrations were maintained at approximately $159.4 \pm 9.7 \mu \mathrm{g} / \mathrm{m}^{3}$ (low concentration) and $319.5 \pm 14.6 \mu \mathrm{g} / \mathrm{m}^{3}$ (high concentration).

\section{Change of body weight and behavioral change}

Male and female mice exposed to FMNPs for one month through nose-only inhalation showed significant reduction of body weight gain at both high and low concentrations of FMNPs (Table 1). One male mouse died in the high concentration group during the exposure period. However, the mice did not show any characteristic behavioral change during the FMNPs inhalation period.

\section{Cell viability and cellular uptake of FMNPs in AMs}

The cell viability was maintained at higher than $95 \%$ in all treated groups (Fig. 1A). However, the AMs were activated by the FMNPs during the 48-h incubation period and cell diameter was greater in the 250 and $1,000 \mu \mathrm{g} / \mathrm{m} l$ groups than in the control group (Fig. 1B). As shown in Fig. 1C and 1D, cellular uptake of FMNPs by AMs was time dependent and FMNPs were only located in the cytosol.

\section{Hematology analysis and histopathological examination}

Hematology analysis showed that inhaled FMNPs significantly increased the numbers of WBC (low and high group) and neutrophils (high group) in male mice (Table $2 \mathrm{~A}$ ). In female mice, significant decreases of $\mathrm{Hb}$ (low and high group), HCT (low) and MCV (low and high group) were observed (Table 2 B). However, the RBC parameter was not changed in male mice. Four weeks inhalation of FMNPs through the nose-only exposure chamber system caused some pathological changes in the Harderian gland, kidney, liver, lung, and nasal cavity, but these changes seemed not to be associated with FMNPs inhalation (Table 3). In contrast, inhaled FMNPs induced extramedullary hematopoiesis (Fig. 2). As shown in low-magnification $(\times 200)$ of the spleen (Fig. 2A), normal spleen (control) consists of discrete white nodules (white pulp, WP), embedded in a red matrix called red pulp (RP) with a dense, fibro-elastic outer capsule (C) which thickens at the hilum and gives rise to supporting connective tissue trabeculae $(\mathrm{T})$ which conduct larger blood vessels throughout the spleen. Compared to normal spleen, FMNPs induced mild increases of extramedullary hematopoiesis in the spleen of mice in a concentration-dependent manner. To get clear pathological results, spleen was examined under mid-magnification $(\times 400$, Fig. $2 B)$. High magnification $(\times 1,000$, Fig. $2 C)$ also confirmed the mild increase of erythroid cells and myeloid cells in the red pulp. Such extramedullary hematopoiesis was clearly found in the red pulp of the spleen of mice exposed to FMNPs.

\section{Discussion}

Occupational safety and health interest in nanomaterials has grown with the development of nanotechnology. Recently, nanomaterials have been introduced to a wide variety of industrial materials, increasing the frequency of human exposure to them. In a previous study, we reported the body distribution of FMNPs inhaled by mice ${ }^{9)}$. We performed the current study to obtain information about the inhalation toxicity of FMNPs.

Our previous study indicated that the nanoparticle generating system we have developed would be useful for inhalation experiments with nanoparticles ${ }^{9)}$. Our results clearly indicate that the spleen was the major organ affected by FMNP inhalation (Fig. 2 and Table 3). The 
A

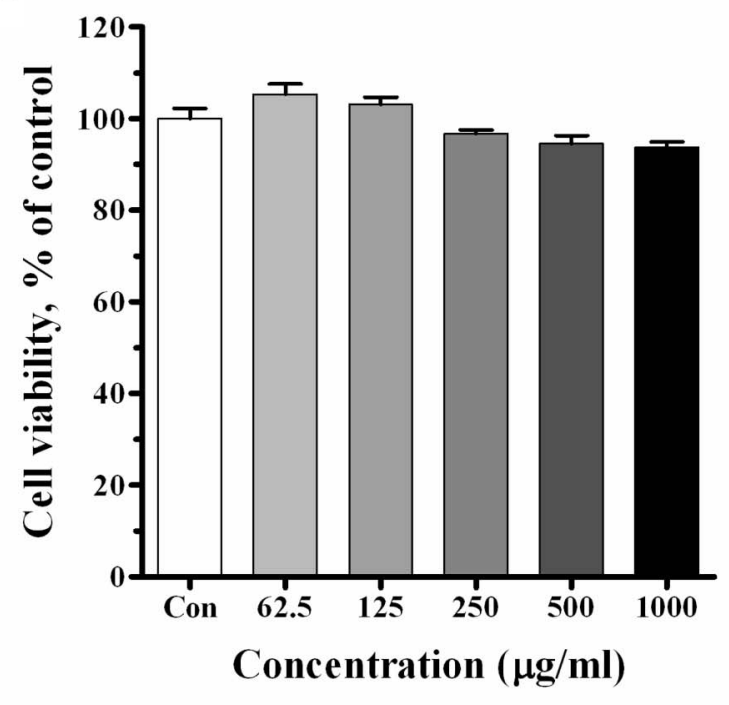

B

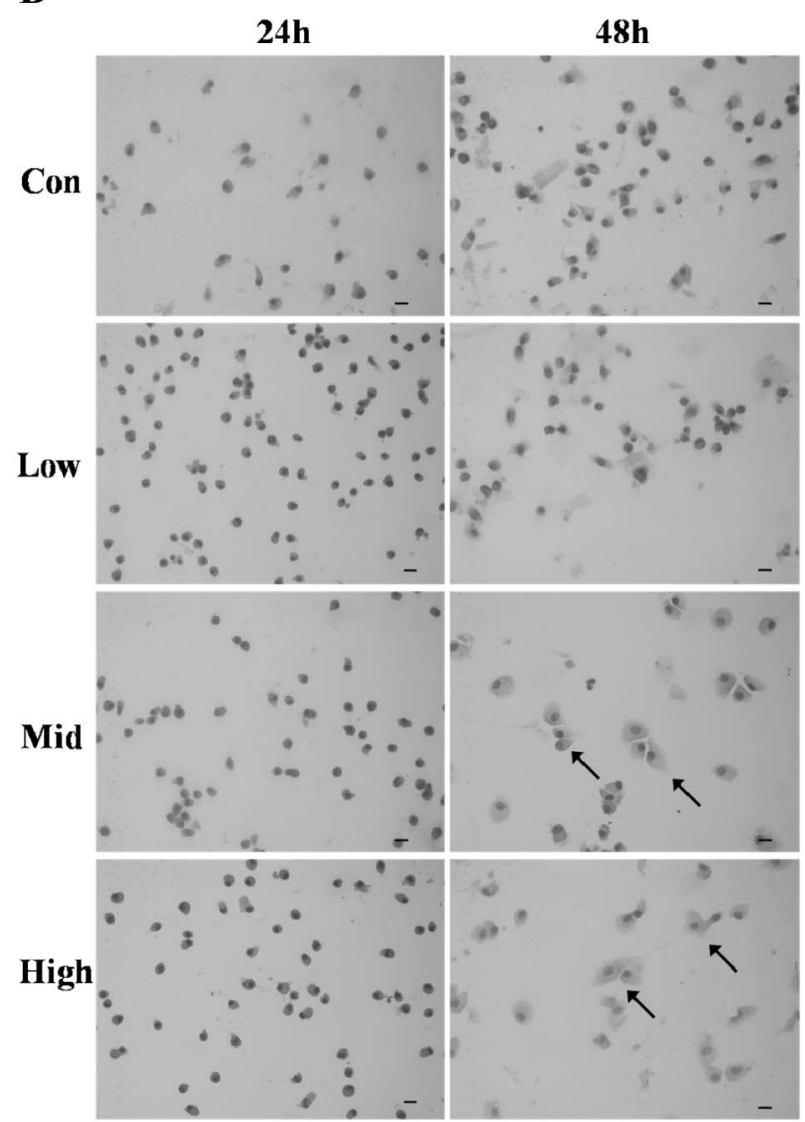

C

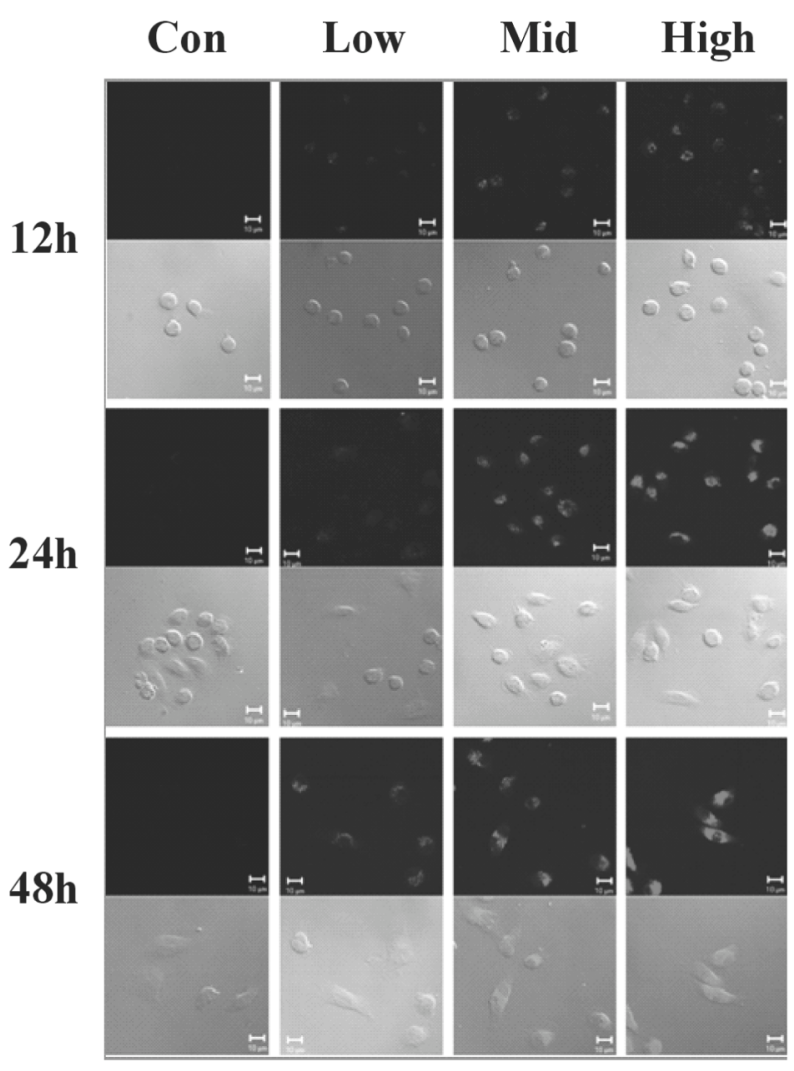

D

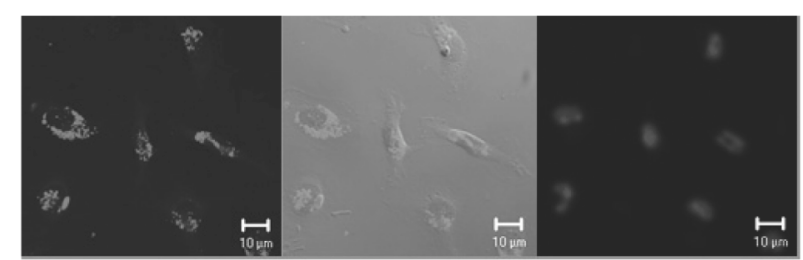

Fig. 1. Effect of various concentrations of FMNPs in alveolar macrophages (AMs). A: Cytotoxicity of AMs after $24 \mathrm{~h}$ incubation with different concentrations of FMNPs. B: Hematoxylin and eosin (H\&E) staining of AMs incubated with FMNPs (high: $1,000 \mu \mathrm{g} / \mathrm{ml}$, mid: $250 \mu \mathrm{g} / \mathrm{m} l$ and low: $62.5 \mu \mathrm{g} / \mathrm{ml}$ ). Arrow: activated AMs. Scale bar: $10 \mu \mathrm{m}$. C: CLSM images of AMs were incubated with 1,000 $\mu \mathrm{g} / \mathrm{m} l$ (High), $250 \mu \mathrm{g} / \mathrm{ml}$ (Mid), $62.5 \mu \mathrm{g} / \mathrm{ml}$ (Low) of FMNPs for 12, 24 and 48 h. Scale bar: 10 $\mu \mathrm{m}$. D: DAPI staining of AMs $(1,000 \mu \mathrm{g} / \mathrm{m} l, 48 \mathrm{~h})$. Left: RITC fluorescence images, Right: DAPI fluorescence images, Center: overlay of the bright-field, RITC and DAPI fluorescence images. Scale bar: $10 \mu \mathrm{m}$. 
Table 2. Hematological values of mice exposed to FMNP inhalation for 4 wk

\begin{tabular}{|c|c|c|c|}
\hline A. Male & & & \\
\hline \multicolumn{4}{|l|}{ Parameter } \\
\hline & Control & Low & High \\
\hline $\mathrm{n}$ & 10 & 10 & 9 \\
\hline $\mathrm{WBC}(\mathrm{K} / \mu l)$ & $2.94 \pm 0.32^{c}$ & $4.42 \pm 1.20^{\mathrm{a}}$ & $5.08 \pm 1.51^{\mathrm{a}}$ \\
\hline NEU (\%) & $21.78 \pm 7.39^{b}$ & $19.74 \pm 6.09^{b}$ & $33.18 \pm 17.05^{\mathrm{a}}$ \\
\hline LYM (\%) & $66.05 \pm 7.43$ & $68.84 \pm 8.31$ & $59.07 \pm 15.75$ \\
\hline MON (\%) & $10.24 \pm 1.98^{\mathrm{a}}$ & $10.47 \pm 3.04^{\mathrm{a}}$ & $5.01 \pm 1.51^{\mathrm{c}}$ \\
\hline EOS (\%) & $1.48 \pm 1.02^{\mathrm{ab}}$ & $0.78 \pm 0.82^{b}$ & $2.04 \pm 1.29 \mathrm{a}$ \\
\hline BAS (\%) & $0.45 \pm 0.23^{\mathrm{ab}}$ & $0.18 \pm 0.34^{\mathrm{b}}$ & $0.71 \pm 0.69^{a}$ \\
\hline $\mathrm{RBC}(\mathrm{M} / \mu l)$ & $9.35 \pm 1.82$ & $11.20 \pm 1.67$ & $10.30 \pm 2.20$ \\
\hline $\mathrm{Hb}(\mathrm{g} / \mathrm{d} l)$ & $13.86 \pm 0.84$ & $14.70 \pm 0.62$ & $13.48 \pm 2.12$ \\
\hline $\operatorname{HCT}(\%)$ & $65.67 \pm 11.44$ & $77.28 \pm 10.62$ & $69.63 \pm 13.76$ \\
\hline MCV (fL) & $71.25 \pm 2.15$ & $69.22 \pm 3.21$ & $62.26 \pm 17.79$ \\
\hline $\mathrm{MCH}(\mathrm{pg})$ & $15.15 \pm 1.86$ & $13.40 \pm 2.06$ & $14.18 \pm 3.79$ \\
\hline $\operatorname{MCHC}(\mathrm{g} / \mathrm{d} l)$ & $21.30 \pm 2.83$ & $19.32 \pm 2.48$ & $19.52 \pm 2.80$ \\
\hline $\operatorname{PLT}(\mathrm{K} / \mu l)$ & $1038.20 \pm 321.42$ & $996.60 \pm 379.65$ & $807.11 \pm 487.98$ \\
\hline \multicolumn{4}{|l|}{ B. Female } \\
\hline \multicolumn{4}{|l|}{ Parameter } \\
\hline & Control & Low & High \\
\hline $\mathrm{n}$ & 10 & 10 & 10 \\
\hline WBC $(\mathrm{K} / \mu l)$ & $3.16 \pm 0.99$ & $4.33 \pm 1.67$ & $3.86 \pm 0.88$ \\
\hline NEU $(\%)$ & $14.58 \pm 3.41$ & $18.83 \pm 6.17$ & $16.41 \pm 6.87$ \\
\hline LYM (\%) & $73.62 \pm 5.43$ & $68.92 \pm 5.08$ & $74.14 \pm 7.73$ \\
\hline $\operatorname{MON}(\%)$ & $8.29 \pm 1.20$ & $7.92 \pm 2.07$ & $6.71 \pm 2.18$ \\
\hline EOS $(\%)$ & $2.59 \pm 1.56$ & $3.21 \pm 1.03$ & $2.17 \pm 1.51$ \\
\hline BAS $(\%)$ & $0.93 \pm 0.70^{\mathrm{ab}}$ & $1.11 \pm 0.44^{\mathrm{a}}$ & $0.56 \pm 0.41^{b}$ \\
\hline $\mathrm{RBC}(\mathrm{M} / \mu l)$ & $10.06 \pm 0.84$ & $8.94 \pm 2.37$ & $10.64 \pm 3.56$ \\
\hline $\mathrm{Hb}(\mathrm{g} / \mathrm{d} l)$ & $15.10 \pm 0.88^{\mathrm{a}}$ & $12.25 \pm 1.24^{\mathrm{c}}$ & $13.02 \pm 1.75^{\mathrm{c}}$ \\
\hline HCT (\%) & $77.50 \pm 5.41^{\mathrm{a}}$ & $57.88 \pm 6.86^{c}$ & $69.80 \pm 11.77^{a}$ \\
\hline MCV (fL) & $80.33 \pm 6.18^{a}$ & $66.85 \pm 9.43^{c}$ & $68.20 \pm 9.45^{\mathrm{c}}$ \\
\hline $\mathrm{MCH}(\mathrm{pg})$ & $15.06 \pm 0.78$ & $14.38 \pm 3.10$ & $13.15 \pm 3.33$ \\
\hline $\mathrm{MCHC}(\mathrm{g} / \mathrm{d} l)$ & $18.83 \pm 1.62^{\mathrm{b}}$ & $21.35 \pm 2.58^{\mathrm{a}}$ & $18.98 \pm 3.07 \mathrm{~b}$ \\
\hline $\operatorname{PLT}(\mathrm{K} / \mu l)$ & $831.30 \pm 229.16$ & $841.10 \pm 390.40$ & $635.20 \pm 330.16$ \\
\hline
\end{tabular}

White blood cell (WBC), neutrophil (NEU), lymphocyte (LYM), monocyte (MON), eosinophil (EOS), basophil (BAS), red blood cell (RBC), hemoglobin (Hb), hematocrit (HCT), mean corpuscular volume (MCV), mean corpuscular hemoglobin $(\mathrm{MCH})$, mean corpuscular hemoglobin concentration (MCHC) and platelet (PLT). Each bar represents the mean $\pm \mathrm{SD}$.

increase of erythroid cells and myeloid cells in the red pulp is consistent with the results of our previous study that inhaled FMNPs were accumulated in specific regions of the spleen ${ }^{9)}$. We counted the number of red dots in the CLSM image of the spleen for semi-quantitative evaluation of the numbers of the nanoparticles in our previous study ${ }^{9}$. The results were: control, $12 \pm 5.66$; low concentration, $129 \pm 32.39$; and high concentration, $137 \pm 64.36$. There was no significant difference between the low group and the high group, however the high group was increased a little more than low. Therefore, to find quantitative effects of FMNPs, we added another lower exposure group, $2.18 \times 10^{5} \# / \mathrm{cm}^{3}$ (Additional exposure group, see supporting text). In the Additional exposure group, the GMD and GSD of the FMNPs were about $50.75 \mathrm{~nm}$ and 1.6, respectively. The additional exposure group also induced extramedullary hematopoiesis in the spleen, male: 5/7, 71.4\%, female: 6/7, 85.7\% (SI Fig. 1). 
A
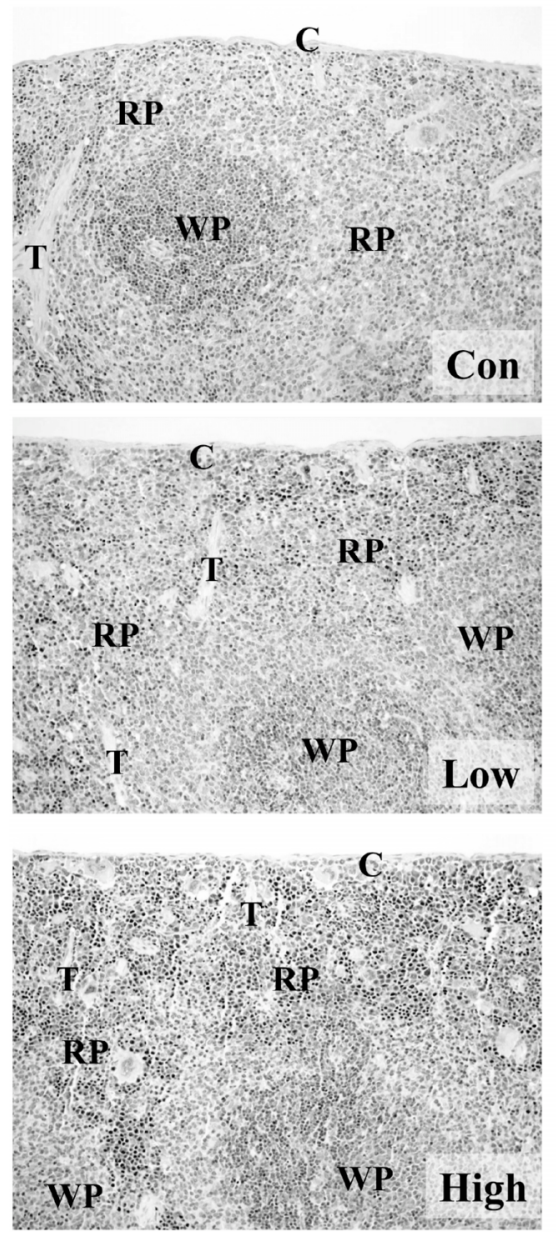

B
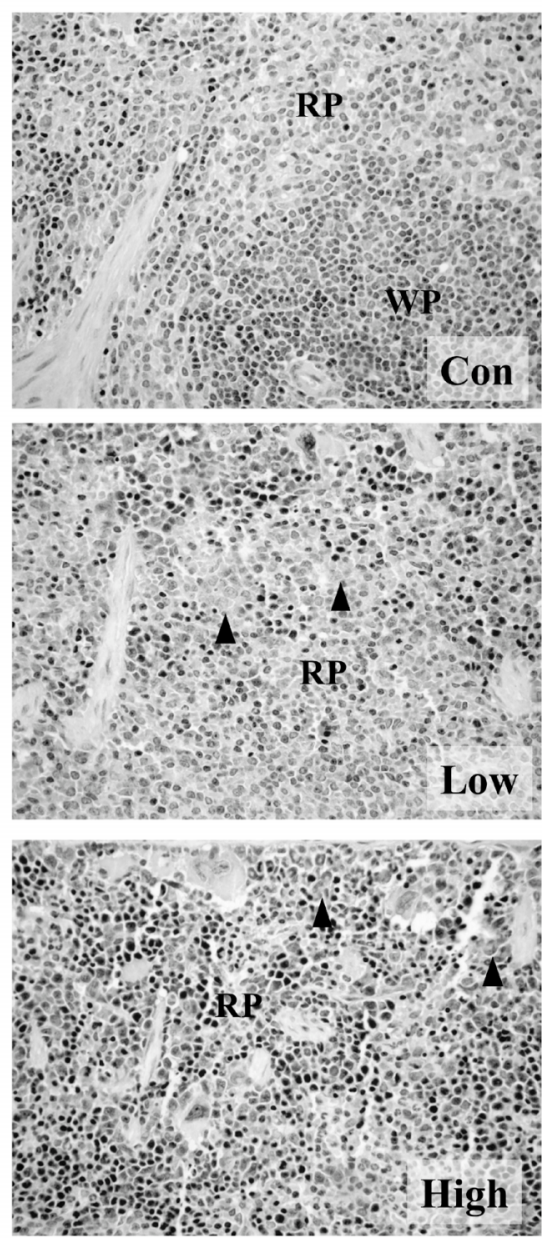

C

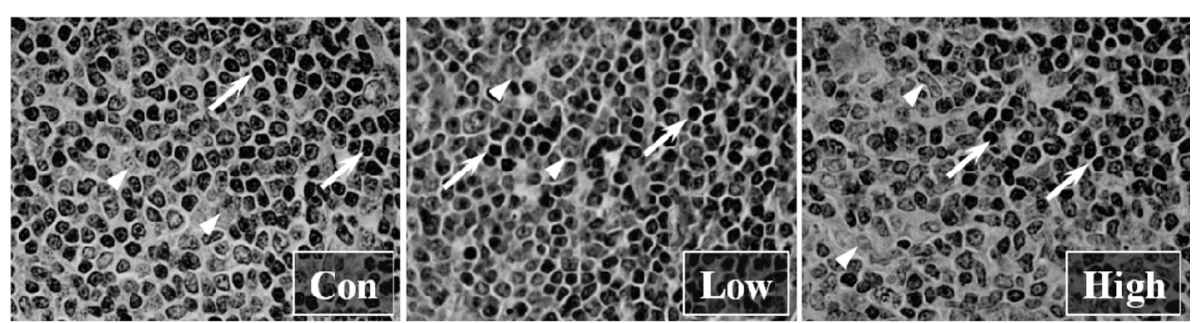

Fig. 2. Histopathological evaluation of the spleen of male mice exposed to FMNP inhalation for $4 \mathrm{wk}$. A: low-magnification $(\times 200)$, note the increased extramedullary hematopoiesis in the red pulp; B: mid-magnification $(\times 400)$, the increased myeloid cells (black arrowheads) in the red pulp; and C: high-magnification $(\times 1,000)$, increased erythroid cells (arrows) and myeloid cells (white arrowheads) in the red pulp. White pulp (WP), Red pulp (RP), Fibro-elastic outer capsule (C), Connective tissue trabeculae (T), Extramedullary hematopoiesis (arrows). Erythroid cells and myeloid cells (open arrowheads). 
Table 3. Summary of histopathological findings in mice exposed with FMNPs for 4 wk

\begin{tabular}{|c|c|c|c|c|c|c|c|}
\hline \multirow[t]{2}{*}{ A. Male } & & \multicolumn{2}{|c|}{ Control } & \multicolumn{2}{|c|}{ Low } & \multicolumn{2}{|c|}{ High } \\
\hline & & $\mathrm{n}$ & $\%$ & $\mathrm{n}$ & $\%$ & $\mathrm{n}$ & $\%$ \\
\hline \multirow[t]{2}{*}{ Spleen } & NM & $8 / 8$ & 100 & $4 / 8$ & 50 & $0 / 7$ & 0 \\
\hline & $\mathrm{EH}$ & $0 / 8$ & 0 & $4 / 8$ & 50 & $7 / 7$ & 100 \\
\hline Lung & NM & $8 / 8$ & 100 & $8 / 8$ & 100 & $7 / 7$ & 100 \\
\hline \multirow[t]{3}{*}{ Nasal cavity } & NM & $8 / 8$ & 100 & $7 / 8$ & 87.5 & $6 / 7$ & 85.7 \\
\hline & GI & $0 / 8$ & 0 & $1 / 8$ & 12.5 & $0 / 7$ & 0 \\
\hline & FA & $0 / 8$ & 0 & $0 / 8$ & 0 & $1 / 7$ & 14.3 \\
\hline \multirow[t]{2}{*}{ Harderian gland } & NM & $5 / 8$ & 62.5 & $6 / 8$ & 75.0 & $3 / 7$ & 42.9 \\
\hline & YLC & $3 / 8$ & 37.5 & $2 / 8$ & 25.0 & $4 / 7$ & 57.1 \\
\hline \multirow[t]{2}{*}{ Kidney } & NM & $8 / 8$ & 100 & $7 / 8$ & 87.5 & $7 / 7$ & 100 \\
\hline & FN & $0 / 8$ & 0 & $1 / 8$ & 12.5 & $0 / 7$ & 0 \\
\hline \multirow[t]{2}{*}{ Liver } & NM & $8 / 8$ & 100 & $7 / 8$ & 87.5 & $7 / 7$ & 100 \\
\hline & FNH & $0 / 8$ & 0 & $1 / 8$ & 12.5 & $0 / 7$ & 0 \\
\hline Brain & NM & $8 / 8$ & 100 & $8 / 8$ & 100 & $7 / 7$ & 100 \\
\hline Trachea & NM & $8 / 8$ & 100 & $8 / 8$ & 100 & $7 / 7$ & 100 \\
\hline Heart & NM & $8 / 8$ & 100 & $8 / 8$ & 100 & $7 / 7$ & 100 \\
\hline Thymus & NM & $8 / 8$ & 100 & $8 / 8$ & 100 & $7 / 7$ & 100 \\
\hline Oculus & NM & $8 / 8$ & 100 & $8 / 8$ & 100 & $7 / 7$ & 100 \\
\hline Adrenal glands & NM & $8 / 8$ & 100 & $8 / 8$ & 100 & $7 / 7$ & 100 \\
\hline Testis & NM & $8 / 8$ & 100 & $8 / 8$ & 100 & $7 / 7$ & 100 \\
\hline \multirow[t]{2}{*}{ B. Female } & & \multicolumn{2}{|c|}{ Control } & \multicolumn{2}{|c|}{ Low } & \multicolumn{2}{|c|}{ High } \\
\hline & & $\mathrm{n}$ & $\%$ & $\mathrm{n}$ & $\%$ & $\mathrm{n}$ & $\%$ \\
\hline \multirow[t]{2}{*}{ Spleen } & $\mathrm{NM}$ & $8 / 8$ & 100 & $0 / 8$ & 0 & $0 / 8$ & 0 \\
\hline & $\mathrm{EH}$ & $0 / 8$ & 0 & $8 / 8$ & 100 & $8 / 8$ & 100 \\
\hline \multirow[t]{2}{*}{ Lung } & $\mathrm{NM}$ & $8 / 8$ & 100 & $8 / 8$ & 100 & $7 / 8$ & 87.5 \\
\hline & $\mathrm{OM}$ & $0 / 8$ & 0 & $0 / 8$ & 0 & $1 / 8$ & 12.5 \\
\hline \multirow[t]{2}{*}{ Nasal cavity } & NM & $8 / 8$ & 100 & $8 / 8$ & 100 & $7 / 8$ & 87.5 \\
\hline & FCD & $0 / 8$ & 0 & $0 / 8$ & 0 & $1 / 8$ & 12.5 \\
\hline \multirow[t]{2}{*}{ Liver } & NM & $7 / 8$ & 87.5 & $8 / 8$ & 100 & $8 / 8$ & 100 \\
\hline & MCI & $1 / 8$ & 12.5 & $0 / 8$ & 0 & $0 / 8$ & 0 \\
\hline \multirow[t]{2}{*}{ Harderian gland } & NM & $5 / 8$ & 62.5 & $2 / 8$ & 25.0 & $3 / 8$ & 37.5 \\
\hline & YLC & $3 / 8$ & 37.5 & $6 / 8$ & 75.0 & $5 / 8$ & 62.5 \\
\hline \multirow[t]{3}{*}{ Kidney } & NM & $7 / 8$ & 87.5 & $8 / 8$ & 100 & $7 / 8$ & 87.5 \\
\hline & $\mathrm{PN}$ & $1 / 8$ & 12.5 & $0 / 8$ & 0 & $0 / 8$ & 0 \\
\hline & $\mathrm{CC}$ & $0 / 8$ & 0 & $0 / 8$ & 0 & $1 / 8$ & 12.5 \\
\hline \multirow[t]{2}{*}{ Adrenal glands } & NM & $6 / 8$ & 75 & $8 / 8$ & 100 & $6 / 8$ & 75 \\
\hline & LP & $2 / 8$ & 25 & $8 / 8$ & 100 & $2 / 8$ & 25 \\
\hline Brain & $\mathrm{NM}$ & $8 / 8$ & 100 & $8 / 8$ & 100 & $8 / 8$ & 100 \\
\hline Trachea & $\mathrm{NM}$ & $8 / 8$ & 100 & $8 / 8$ & 100 & $8 / 8$ & 100 \\
\hline Heart & $\mathrm{NM}$ & $8 / 8$ & 100 & $8 / 8$ & 100 & $8 / 8$ & 100 \\
\hline Thymus & NM & $8 / 8$ & 100 & $8 / 8$ & 100 & $8 / 8$ & 100 \\
\hline Oculus & $\mathrm{NM}$ & $8 / 8$ & 100 & $8 / 8$ & 100 & $8 / 8$ & 100 \\
\hline Ovary & $\mathrm{NM}$ & $8 / 8$ & 100 & $8 / 8$ & 100 & $8 / 8$ & 100 \\
\hline
\end{tabular}

NM: no microscopic finding, EH: extramedullary hematopoiesis, OM: osseous metaplasia, FCD: focal chronic dermatitis, MCI: mononuclear cell infiltration, YLC: yellow-brown laminated concretion, PN: pyelonephritis, CC: cortical cyst, LP: lipidosis. GI: granulomatous inflammation, FA: focal acanthosis, FN: focal nephropathy and FNH: focal necrotizing hepatitis. Samples were stained with hematoxilin and eosin (H\&E) and observed under a light microscope. 
Histopathology showed extramedullary hematopoiesis in the spleen whereas other organs examined did not show any significant changes.

The spleen was not affected by i.p. administration of FMNPs in our previous study ${ }^{10}$. Such a difference in toxicity is quite interesting when we consider the concentrations used in each study $(25,50$ and $100 \mathrm{mg} / \mathrm{kg}$ for i.p. vs 150 and $300 \mu \mathrm{g} / \mathrm{m}^{3}$ for inhalation). The i.p. injected FMNPs would be taken up by the liver via the first-pass effects and then redistributed from the liver to the other organs. In contrast, inhaled FMNPs absorbed through the lung are not sent directly to the liver. Although the liver is regarded as the most important organ in the process of phagocytosis, the spleen, lung, lymphatic system and bone marrow are also involved ${ }^{11}$. The spleen and liver cooperatively contribute to hematopoietic homeostasis along with bone marrow during ontogeny and extramedullary hematopoiesis in adult life is usually associated with pathological conditions ${ }^{12}$. Extramedullary hematopoiesis is the proliferation of hematopoietic cells outside of the bone marrow in anemic states. The most frequent sites of extramedullary hematopoiesis include the spleen, liver and kidney ${ }^{13)}$. Alveolar macrophages are key effectors cells of the innate immune response in the lung ${ }^{14)}$. In the previous study, inhaled ambient particles affected AMs and these cells produced immune response mediators in the lung. Moreover, these immune responses stimulated the bone marrow $^{15-17)}$. Our present results show that cellular uptake of FMNPs was time dependent and AMs were activated by FMNPs without cell death (Fig. 1). Also, hematology analysis showed that inhaled FMNPs decreased the mean corpuscular volume (MCV) and mean corpuscular hemoglobin $(\mathrm{MCH})$ in both male and female mice (Table 2 ). Although the platelet count was a no significant difference between control group and exposure groups, platelet count in the exposed groups was less than in the control group in male (low and high) and female (high group) mice (Table 2). The toxicity of amorphous silica is characterized as being less toxic than crystalline forms in experimental animals ${ }^{18)}$. However, intratracheal instillation of amophorus silica in mice induces dose- and size-dependent pulmonary effects, with nanoparticles inducing greater lung inflammation and tissue damage than larger particles ${ }^{19)}$. In this study, FMNPs coated with amorphous silica did not induce pulmonary toxicity in the histopathalogical analysis.

Taken together, these findings suggest that inhaled FMNPs may affect production of platelets and WBC in bone marrow, which in turn induces extramedullary hematopoiesis in the spleen without causing a pulmonary effect.

Many nanomaterial inhalation toxicity studies have focused on the pulmonary effect and clearances in the lung. While the pulmonary toxicity of nanomaterials is widely known, there is limited information regarding the systemic toxicity of nanomaterials. Some nanomaterials can penetrate the central nervous system and lung and enter the circulatory and lymphatic systems $9,20,21)$. Therefore, the systemic effect of nanomaterials is even more important than their local effect in inhalation.

In summary, inhalation of FMNPs caused a decrease in body weight gain and a significant change in the number of WBCs in whole blood. Furthermore, FMNPs induced extramedullary hematopoiesis in the spleen. Based on these results, Our results support the hypothesis that extensive systemic toxicity evaluation is needed for practical applications of anthropogenic nanomaterials and suggest that careful regulation of nanoparticle applications may be necessary to maintain a high quality of life as well as for facilitating the development of nanotechnology.

Acknowledgments: Parts of the current study were supported by a research grant (\#2009-0082737) from the National Research Foundation (NRF) of Korea. J.T.K., S.K.H., A.M-T., X.X.C., K.J.E, E.S.L. and L.H.T. are grateful for financial support from the BK21 program. J.K.L. and M.H.C. thank the Nano Systems InstituteNational Core Research Center (NSI-NCRC) for their support through Korean Science and Engineering Foundation (KOSEF).

\section{References}

1) Oberdörster G, Oberdörster E, Oberdörster J. Nanotoxicology: An emerging discipline evolving from studies of ultrafine particles. Environ Health Perspect 2005; 113: 823-39.

2) Inoue $K$, Takano H, Yanagisawa R, et al. Effects of airway exposure to nanoparticles on lung inflammation induced by bacterial endotoxin in mice. Environ Health Perspect 2005; 114: 1325-30.

3) Olbrich C, Scholer N, Tabatt K, Kayser O, Muller RH. Cytotoxicity studies of Dynasan 114 solid lipid nanoparticles (SLN) on RAW 264.7 macrophagesimpact of phagocytosis on viability and cytokine production. J Pharm Pharmacol 2004; 56: 883-91.

4) Shvedova AA, Kisin ER, Mercer R, et al. Unusual inflammatory and fibrogenic pulmonary responses to single-walled carbon nanotubes in mice. Am J Physiol Lung Cell Mol Physiol 2005; 289: L698-708.

5) Perez JM, Simeone FJ, Saeki Y, Josephson L, Weissleder R. Viral-induced self-assembly of magnetic nanoparticles allows the detection of viral particles in biological media. J Am Chem Soc 2003; 125: 10192-3.

6) Song Q, Zhang ZJ. Shape control and associated magnetic properties of spinel cobalt ferrite nanocrystals. J Am Chem Soc 2004; 126: 6164-8.

7) Li W, Ma N, Ong LL, et al. Enhanced thoracic gene delivery by magnetic nanobead-mediated vector. $\mathrm{J}$ Gene Med 2008; 10: 897-909.

8) Yoon TJ, Kim JS, Kim BG, Yu KN, Cho MH, Lee JK. 
Multifunctional nanoparticles possessing a "magnetic motor effect" for drug or gene delivery. Angew Chem Int Ed Engl 2005; 44: 1068-71.

9) Kwon JT, Hwang SK, Jin H, et al. Body distribution of inhaled fluorescent magnetic nanoparticles in mice. J Occup Health 2008; 50: 1-6.

10) Kim JS, Yoon TJ, Yu KN, et al. Toxicity and tissue distribution of magnetic nanoparticles in mice. Toxicol Sci 2006; 89: 338-47.

11) Borchard G, Kreuter J. The role of serum complement on the organ distribution of intravenously administered poly (methyl methacrylate) nanoparticles: Effects of pre-coating with plasma and with serum complement. Pharm Res 1996; 13: 1055-8.

12) Wolber FM, Leonard E, Michael S, Orschell-Traycoff CM, Yoder MC, Srour EF. Roles of spleen and liver in development of the murine hematopoietic system. Exp Hematol 2002; 30: 1010-9.

13) Dibbern DA Jr, Loevner LA, Lieberman AP, Salhany KE, Freese A, Marcotte PJ. MR of thoracic cord compression caused by epidural extramedullary hematopoiesis in myelodysplastic syndrome. Am J Neuroradiol 1997; 18: 363-6.

14) Holt PG. Inhibitory activity of unstimulated alveolar macrophages on T-lymphocyte blastogenic response. Am Rev Respir Dis 1978; 118: 791-3.

15) Van Eeden SF, Hogg JC. Systemic inflammatory response induced by particulate matter air pollution: the importance of bone-marrow stimulation. J Toxicol Environ Health A 2002; 65: 1597-613.

16) Mukae H, Vincent R, Quinlan K, et al. The effect of repeated exposure to particulate air pollution (PM10) on the bone marrow. Am J Respir Crit Care Med 2001; 163: 201-9.

17) Goto Y, Ishii H, Hogg JC, et al. Particulate matter air pollution stimulates monocyte release from the bone marrow. Am J Respir Crit Care Med 2004; 170: 891-7.

18) Warheit DB, McHugh TA, Hartsky MA. Differential pulmonary responses in rats inhaling crystalline, colloidal or amorphous silica dusts. Scand J Work Env Hea 1995; 2: 19-21.

19) Kaewamatawong T, Kawamura N, Okajima M, Sawada M, Morita T, Shimada A. Acute pulmonary toxicity caused by exposure to colloidal silica: Particle size dependent pathological changes in mice. Toxicol Pathol 2005; 33: 743-9.

20) Oberdörster G, Sharp Z, Atudorei V, et al. Translocation of inhaled ultrafine particles to the brain. Inhal Toxicol 2004; 16: 437-45.

21) Semmler M, Seitz J, Erbe F, et al. Long-term clearance kinetics of inhaled ultrafine insoluble iridium particles from the rat lung, including transient translocation into secondary organs. Inhal Toxicol 204; 16: 453-9.

\section{Appendix:}

Supporting Information Fig. 1.

Histological analysis of the spleen from mice exposed to FMNPs $(50.75 \mathrm{~nm}$, total particle number concentration: $2.18 \times 10^{5} / \mathrm{cm}^{3}$ ). Hematoxylin and Eosin (H\&E) staining. Left: control, Right: exposure group. Upper: low-magnification $(\times 200)$, Lower: high-magnification $(\times 400)$. WP: white pulp. RP: red pulp. C: fibro-elastic outer capsule. Arrows: extramedullary hematopoiesis.

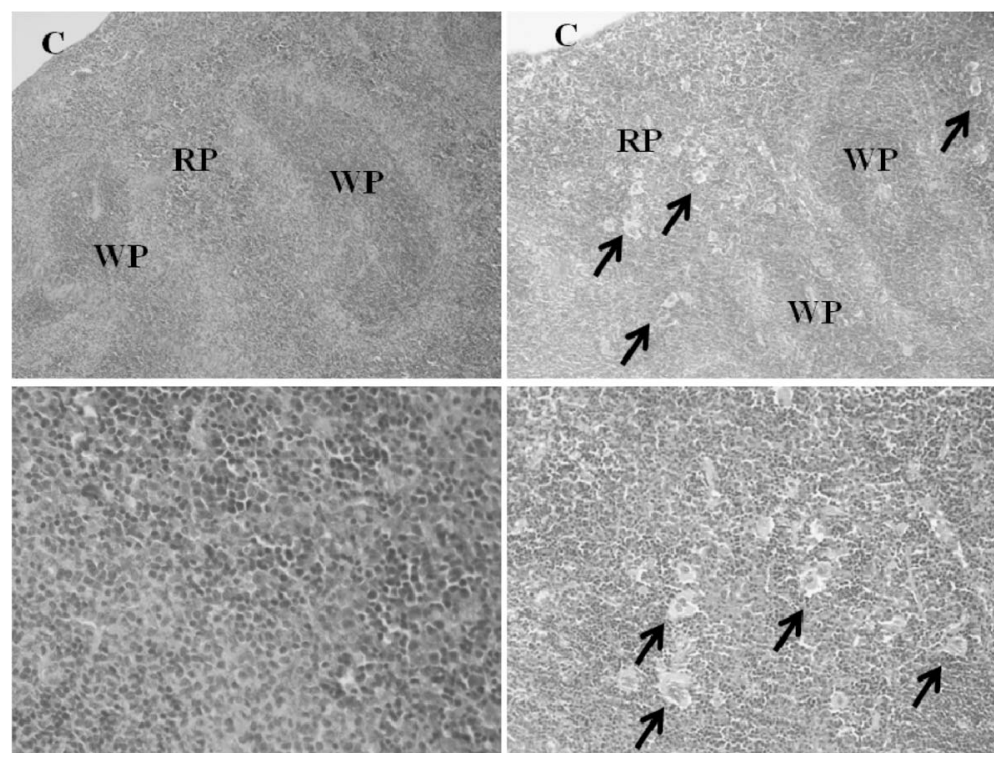

